disease duration at entry ( 4.8 vs 0.5 years). In the first equation predicting change in annual SLEDAI score, predictors were generally aligned with the same direction and significance, with the exception of renal involvement in the prior period, which had a positive association with change in SLEDAI in the SLICC cohort but was negatively associated in the $\mathrm{JH}$ cohort (Table 1). The second equation predicting prednisone dose was also consistent with the original analysis showing a significant positive association between higher disease activity and prednisone use. In all of the parametric survival analyses (individual organ damage and mortality models), coefficients were generally in the same direction and magnitude, though some were no longer significant in the SLICC cohort.

Conclusion: The relationships identified in the original analysis were broadly replicated in the SLICC Inception Cohort. Observed differences may reflect differences in the patient populations, structure of the two cohorts (prevalent vs inception), and frequency of visits (quarterly visits in the $\mathrm{JH}$ cohort vs annual visits with the SLICC cohort may more closely capture a decrease in SLEDAI associated with treatment specifically related to renal involvement). Additional analyses relaxing the requirement to completely align with the original structure are underway to further assess the predictive accuracy of these models. REFERENCES:

[1] Watson P, et al. Rheumatology (Oxford). 2015;54(4):623-32.

Table 1.

\begin{tabular}{|c|c|c|c|c|}
\hline & $\begin{array}{l}\text { JH Cohort } \\
(\mathrm{N}=1354)\end{array}$ & & $\begin{array}{l}\text { SLICC Cohor } \\
\qquad(N=1697)\end{array}$ & \\
\hline Female, \% & 92.9 & & 88.8 & \\
\hline African descent, \% & 38.8 & & 16.7 & \\
\hline Disease duration at entry, mean (SD), years & $4.8(6.3)$ & & $0.5(0.3)$ & \\
\hline SLEDAI at first visit, mean (SD) & $3.7(4.1)$ & & $5.4(5.4)$ & \\
\hline Change in average annual SLEDAI & Coefficient & & Coefficient & \\
\hline Constant & 1.491 & * & 5.762 & * \\
\hline Annual average SLEDAI in prior period & -0.460 & * & -0.755 & * \\
\hline Male gender & -0.080 & & -0.207 & \\
\hline Log transformation of age & -0.241 & * & -1.134 & * \\
\hline Renal involvement in prior period & -0.301 & * & 0.627 & * \\
\hline African descent & 0.383 & * & 0.126 & \\
\hline Increased DNA binding in prior period & 0.276 & * & 0.939 & * \\
\hline Low complement in prior period & 0.484 & * & 0.775 & * \\
\hline Hematological involvement in prior period & 0.104 & & -0.025 & \\
\hline Anemia in prior period & 0.152 & ** & 0.144 & \\
\hline \multicolumn{5}{|c|}{ Associated annual average prednisone dose (mg/day) } \\
\hline Constant & 3.475 & * & 2.738 & * \\
\hline SLEDAI in same period & 0.777 & * & 0.648 & * \\
\hline
\end{tabular}

${ }^{*} \mathrm{p}<0.001 ;{ }^{* *} \mathrm{p}<0.05$

Acknowledgements: We acknowledge the support on this abstract of the following investigators of the Systemic Lupus International Collaborating Clinics: John Hanly - john.hanly@ nshealth.ca

Caroline Gordon - p.c.gordon@ bham.ac.uk

Sang-Cheol Bae - scbae@ hanyang.ac.kr

Juanita Romero-Diaz - juanita.romerodiaz@ gmail.com

Jorge Sanchez-Guerrero - jorge.sanchez-guerrero@uhn.ca

Sasha Bernatsky - sasha.bernatsky@mcgill.ca

Ann Clarke - aeclarke@ucalgary.ca

Daniel Wallace - dwallace@ucla.edu/danielwallac@gmail.com

David Isenberg - d.isenberg@ucl.ac.uk

Anisur Rahman - anisur.rahman@ucl.ac.uk

Joan Merril - JTMmail@aol.com

Paul Fortin - paul.fortin@ crchudequebec.ulaval.ca

Dafna Gladman - dafna.gladman@ utoronto.ca

Murray Urowitz - m.urowitz@utoronto.ca

lan Bruce - ian.bruce@manchester.ac.uk

Michelle Petri - mpetri@jhmi.edu

Ellen Ginzler - ellen.ginzler@downstate.edu

MA Dooley - Mary_Dooley@med.unc.edu

Rosalind Ramsey-Godman - rgramsey@northwestern.edu

Susan Manzi - susan.manzi@ahn.org; Susanmanzi@gmail.com

Andreas Jonsen - andreas.jonsen@med.lu.se

Graciela Alarcon - galarcon@uab.edu

Ronald van Vollenhoven - r.vanvollenhoven@amsterdamumc.nl

Cynthia Aranow - CAranow @ Northwell.edu

Meggan Mackay - mmackay@northwell.edu

Guillermo Ruiz-Irastorza - r.irastorza@outlook.es

Sam Lim - sslim@emory.edu

Murat Inanc - drinanc@istanbul.edu.tr; minanc2008@gmail.com

Kenneth Kalunian - kkalunian@ucsd.edu

Soren Jacobsen - sj@ dadlnet.dk
Christine Peschken - christine.peschken@umanitoba.ca

Diane Kamen - kamend@musc.edu

Anca Askanase - ada20@ columbia.edu

Disclosure of Interests: Ann E Clarke Consultant of: BMS, AstraZeneca, GSK, and Exagen Diagnostics., Yvan St-Pierre: None declared, Victoria Paly: None declared, Ian N. Bruce Speakers bureau: GSK, UCB, Consultant of: BMS, El Lilly, GSK, Astra Zeneca, Merck Serono; UCB, ILTOO, Aurinia, Grant/research support from: Genzyme/Sanofi, GSK, Roche, UCB, Chiara Malmberg: None declared, Andrew Briggs Speakers bureau: Alexion, AstraZeneca, Bayer, BMS Daiichi Sankyo, Eisai, Gilead, GSK, Kite, Merck, Novartis, Rhythm, Roche Sanofi, Takeda, Consultant of: Alexion, AstraZeneca, Bayer, BMS, Daiichi Sankyo, Eisai, Gilead, GSK, Kite, Merck, Novartis, Rhythm, Roche, Sanofi, Takeda Yuanhui Zhang Shareholder of: Bristol Myers Squibb., Employee of: Bristol Myers Squibb., Jiyoon Choi Shareholder of: JNJ., Employee of: BMS, Alan Brennan Consultant of: Alan Brennan is a paid consultant on advisory boards regarding cost-effectiveness modelling., Grant/research support from: Alan Brennan received research grants.

DOI: 10.1136/annrheumdis-2021-eular.1790

\section{POS0735 \\ ULTRASOUND-GUIDED CORE NEEDLE BIOPSY FOR SALIVARY GLAND ENLARGEMENT IN SJÖGREN'S SYNDROME: PROCEDURE SAFETY AND PATIENT TOLERANCE}

A. Zabotti ${ }^{1}$, I. Giovannini ${ }^{1}$, S. Z. Callegher ${ }^{1}$, V. Manfrè ${ }^{1}$, M. Lorenzon ${ }^{2}$, E. Pegolo ${ }^{3}$, C. A. Scott ${ }^{3}$, A. Tel ${ }^{4}$, M. Robiony ${ }^{4}$, C. Zuiani ${ }^{2}$, S. De Vita ${ }^{1}$. ${ }^{1}$ Rheumatology Clinic, Department of Medicine, University of Udine, c/o Azienda Sanitaria Universitaria Friuli Centrale, Udine, Italy; ${ }^{2}$ Institute of Radiology, Dipartimento di Diagnostica per Immagini, Udine, Italy; ${ }^{3}$ Institute of Anatomic Pathology, Department of Medical and Biological Sciences, Udine, Italy; ${ }^{4}$ Maxillofacial Surgery, Department of Specialistic Surgery, Udine, Italy

Background: Persistent enlargement of major salivary glands (SGs) is one of the main risk factors for B-cell lymphoma in primary Sjögren's syndrome (pSS) The Ultrasound-guided Core Needle Biopsy (US-guided CNB) could be a novel technique for the management of SGs enlargement in pSS (1).

Objectives: To evaluate the procedure safety and the patient tolerance of US-guided CNB in pSS patients with major SGs enlargement.

Methods: Consecutive patients, with either definite or clinically suspected pSS and with clinical indication for SGs biopsy due to persistent glandular enlargement were screened for US-guided CNB from September 2019 to December 2020. All patients were evaluated clinically between 1 and 2 weeks and 12 weeks following US-guided CNB. All patients were asked to complete a questionnaire to report post-procedural complications (Figure 1, English version) and intra- and post-procedural pain Visual Analogue Scale (VAS). The complications were classified as transient ( $<12$ weeks) or persistent ( $\geq 12$ weeks).

Results: US-guided CNB was performed in 21 glands (12 parotid and 9 submandibular glands) in 20 pSS patients. 16/20 (80\%) patients fulfilled the ACR-EULAR classification criteria for pSS (2). The mean age at the time of biopsy was 62.1 $( \pm 11.7)$ years. US-guided CNB was well tolerated, no long-term complications were reported in the follow-up period (mean $9.5 \pm 5.7$ months). Only transient complications were noticed in 11 patients $(55 \%)$. In particular, two cases of local swelling at the biopsy site lasting no more than 6 days, one case of local bleeding and subsequently hematoma of the submandibular area, one case of transient facial paresis (lasting less than one hour), seven cases of post-procedural mild local pain, that resolved within 10 days without the need of analgesics (Table 1) The procedure was well tolerated, with a very low reported intra-operative pain (mean VAS $1.74 \pm 2.49$ ) and a mean post-operative pain VAS of $1.39( \pm 2.33)$. The biopsy sampling was diagnostic in 19/20 patients (95\%).

Conclusion: US-guided CNB represents a novel approach for the management of pSS patients with SGs enlargement. This procedure shows a remarkable patient safety and tolerance, allowing an adequate glandular sampling and definite diagnosis in almost all the studied patients.

REFERENCES:

[1] Zabotti A, Zandonella Callegher S, Lorenzon M, Pegolo E, Scott CA, Tel A, et al. Ultrasound-guided core needle biopsy compared with open biopsy: a new diagnostic approach to salivary gland enlargement in Sjögren's syndrome? Rheumatology (Oxford) 2020

[2] Shiboski CH, Shiboski SC, Seror R, Criswell LA, Labetoulle M, Lietman TM, Rasmussen A, Scofield H, Vitali C, Bowman SJ, Mariette X; International Sjögren's Syndrome Criteria Working Group. 2016 American College of Rheumatology/European League Against Rheumatism Classification Criteria for Primary Sjögren's Syndrome: A Consensus and Data-Driven Methodology Involving Three International Patient Cohorts. Arthritis Rheumatol 2017 Jan;69(1):35-45. doi: 10.1002/art.39859. Epub 2016 Oct 26. PMID: 27785888 ; PMCID: PMC5650478. 
Table 1. Description of complications

\section{Complications of US-guided CNB}

Patients presenting complications, $n / N(\%)$

Description of transient complications

Swelling at biopsy site, $n$

Bleeding, $n$

Hematoma, $n$

Local Pain, $n$

Local infection, $n$

Sialocele or fistula, $n$

Anaesthesia/paraesthesia, $n$

Transient facial palsy ( $<1$ hour $), n$

No persistent complications reported

All the above specified complications were transient ( $<12$ weeks). No persistent complications were reported in the follow up.

\section{POST-BIOPSY COMPLICATIONS QUESTIONNAIRE}

\begin{tabular}{|c|c|c|}
\hline $\begin{array}{l}\text { 1. Did you have any swelling at biopsy site? } \\
\text { If yes, how long? }\end{array}$ & YES & $\mathrm{NO}$ \\
\hline Physician control & YES & NO \\
\hline 2. Did you have any hematoma at biopsy site? & YES & $\mathrm{NC}$ \\
\hline $\begin{array}{l}\text { If yes, how long? } \\
\text { Physician control }\end{array}$ & Y...... & NO \\
\hline 3. Did you have any bleeding at biopsy site? & YES & NO \\
\hline If yes, how long? & & \\
\hline Physician control & YES & NO \\
\hline 4. Did you have pain at biopsy site? & YES & NO \\
\hline $\begin{array}{l}\text { If yes, choose a number from } 0 \text { to } 10 \text { to describe pain intensity } \\
\text { If yes, how long? }\end{array}$ & 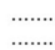 & \\
\hline 5. Did you have any local infection? & YES & NO \\
\hline Physician control & YES & NO \\
\hline 6. Did you have any anesthesia / paresthesia in the biopsy area? & YES & NO \\
\hline If yes, how long? & ........ & \\
\hline Physician control & YES & NO \\
\hline 7. Did you have any sialocele or fistula in the biopsy area? & YES & NO \\
\hline Physician control & YES & NO \\
\hline
\end{tabular}

Figure 1. Post-biopsy complication Questionnaire

Disclosure of Interests: Alen Zabotti Speakers bureau: UCB, Novartis, Janssen, Paid instructor for: Amgen, Consultant of: Janssen, Ivan Giovannini: None declared, Sara Zandonella Callegher: None declared, Valeria Manfrè: None declared, Michele Lorenzon Consultant of: not relevant for this study, Enrico Pegolo: None declared, Cathryn Ann Scott: None declared, Alessandro Tel: None declared, Massimo Robiony Consultant of: not relevant for this study, Grant/ research support from: not relevant for this study, Chiara Zuiani Consultant of: not relevant for this study, Grant/research support from: not relevant for this study, Salvatore De Vita Consultant of: GSK, Roche, Grant/research support from: not relevant for this study

DOI: 10.1136/annrheumdis-2021-eular.1804

\section{POS0736 IDENTIFICATION OF MOLECULAR PHENOTYPES AND IMMUNE CELL INFILTRATION IN SYSTEMIC LUPUS ERYTHEMATOSUS PATIENTS ACCORDING TO LONGITUDINAL GENE EXPRESSION}

S. Song ${ }^{1,2,3}$, S. X. Zhang ${ }^{1,2,3}$, J. Qiao ${ }^{1,2,3}$, R. Zhao ${ }^{1,2,3}$, J. Shi ${ }^{1,2,3}$, Y. Hu ${ }^{1,2,3}$, J. Chen ${ }^{1}$, G. Y. Liu ${ }^{1}$, P. F. He ${ }^{4}$, X. Li ${ }^{1,2,3}$. ${ }^{1}$ The Second Hospital of Shanxi Medical University, Department of Rheumatology, Taiyuan, China; ${ }^{2}$ Shanxi Li Xiaofeng Medical Groups, Department of Rheumatology, Taiyuan, China; ${ }^{3}$ Ministry of Education, Key Laboratory of Cellular Physiology at Shanxi Medical University, Taiyuan, China; ${ }^{4}$ Shanxi Medical University, Institute of Medical Data Sciences, Taiyuan, China

Background: Systemic lupus erythematosus (SLE) is a chronic autoimmune disease with highly heterogeneous clinical presentation characterized by disease unpredictable flares and multi-systemic involvement ${ }^{12}$. This clinical heterogeneity calls for design a molecular stratification to improve clinical trial design and formulate personalization treatment therapies.
Objectives: This research was conducted to develop a reliable method to stratify SLE patients combined gene expression information and disease status.

Methods: The mRNA expression profile of GSE138458 (contained 307 patients and 23 controls) and GSE49454 (contained 111 patients and 16 controls) were downloaded from the publicly GEO databases. After background adjustment, batch correction, and other pre-procession, obtaining a big gene matrix to identify the differentially expressed genes (DEGs) in SLE compared with healthy controls, which were screened by $P$ value $<0.01$. SLE subtypes were identified by non-negative matrix factorization (NMF) based on DEGs. Acquired signature genes in different SLE subtypes were conducted to process pathway enrichment analysis in Metascape. SLEDAI score and immune cell infiltration was also performed between subtypes by software package $R$ (version 4.0.3)

Results: Total 1202 DEGs were imputed to NMF unsupervised machine learning method. Patients with SLE were stratified into two subsets based on 184 signature genes derived from obtained DEGs(Fig.1A, 1B). GO and KEGG enrichment analysis showed that signature genes were mainly involved in negative regulation of innate immune response, toll-like receptor signaling pathway, regulation of immune effector process and so on(Fig.1C). Patients in Sub1 group had severe disease activity measures compared with those in Sub2(Fig.1D). SLEDA scores from GSE49454 dataset were also higher in Sub1 compare with Sub2(Fig.1E). Further, immune cell infiltration results revealed an insufficient of regulatory T cell, CD8 T cells and naive CD4 T cells in Sub1 and neutrophils cells in Sub2 $(P<0.05)$ (Fig.1F).

Conclusion: Our findings indicate that patients with SLE could be stratified into 2 subtypes which had different lymphocyte status and closely related to disease activity. This phenotyping may help us understand the etiology of the disease, inform patient in the design of clinical trials and guide treatment decision.

\section{REFERENCES:}

[1] Dorner T, Furie R. Novel paradigms in systemic lupus erythematosus. Lancet 2019;393(10188):2344-58. doi: 10.1016/S0140-6736(19)30546-X [published Online First: 2019/06/11].

[2] Fanouriakis A, Tziolos N, Bertsias G, et al. Update on the diagnosis and management of systemic lupus erythematosus. Annals of the rheumatic diseases 2021;80(1):14-25. doi: 10.1136/annrheumdis-2020-218272 [published Online First: 2020/10/15]

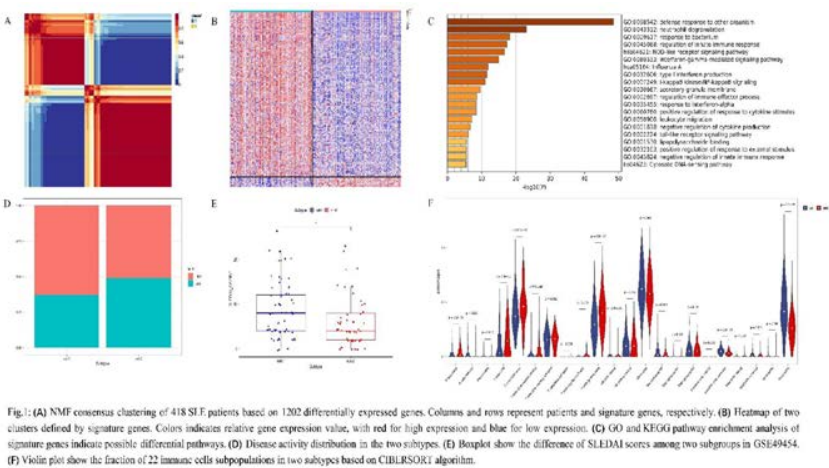

Acknowledgements: This project was supported by National Science Foundation of China (82001740), Open Fund from the Key Laboratory of Cellular Physiology (Shanxi Medical University) (KLCP2019) and Innovation Plan for Postgraduate Education in Shanxi Province (2020BY078).

Disclosure of Interests: None declared

DOI: 10.1136/annrheumdis-2021-eular.1812

\section{POS0737 LOW PRECONCEPTIONAL COMPLEMENT LEVEL IS RELATED WITH ADVERSE OBSTETRIC OUTCOME IN A MULTICENTRIC COHORT OF PREGNANCY IN PATIENTS WITH APS AND APL POSITIVITY}

D. Lini ${ }^{1}$, C. Nalli ${ }^{1}$, L. Andreoli ${ }^{1}$, F. Crisafulli ${ }^{1}$, M. Fredi ${ }^{1}$, M. G. Lazzaroni ${ }^{1}$, V. Bitsadze ${ }^{2}$, A. Calligaro ${ }^{3}$, V. Canti ${ }^{4}$, R. Caporali ${ }^{5}$, F. Carubbi $^{6}$, C. Chighizola ${ }^{7}$, P. Conigliaro ${ }^{8}$, F. Conti ${ }^{9}$, C. De Carolis ${ }^{10}$, T. Del Ross ${ }^{11}$, M. Favaro ${ }^{11}$, M. Gerosa ${ }^{12}$, A. Iuliano $^{13}$, J. Khizroeva ${ }^{2}$, A. Makatsariya ${ }^{2}$, P. L. Meroni ${ }^{12}$, M. Mosca ${ }^{14}$, P. Melissa ${ }^{15}$, R. Perricone ${ }^{8}$, P. Rovere-Querini ${ }^{16}$, G. D. Sebastiani ${ }^{13}$, C. Tani ${ }^{12}$, M. Tonello ${ }^{11}$, S. Truglia ${ }^{9}$, D. Zucchi ${ }^{12}$, F. Franceschini ${ }^{1}$, A. Tincani ${ }^{1}$. ${ }^{1}$ University and ASST Spedali Civili of Brescia, Rheumatology Unit, Brescia, Italy; ${ }^{2}$ I.M. Sechenov First Moscow State Medical University of the Ministry of Health of the Russian Federation (Sechenov University), Department of Obstetrics and Gynecology, Moscow, Russian Federation; ${ }^{3}$ University Hospital of Padua, Padua, Rheumatology Unit, Department of Medicine, Padua, Italy 